

NOTE

\title{
Scaleup Condensation Process in Preparation of Flumorph
}

\author{
Dequn Sun ${ }^{1, *}$, Changyan Hu${ }^{1}$ and Yue YanG ${ }^{2}$
}

${ }^{1}$ Marine College, Shandong Univerity at Weihai, No. 180, Weihai West Road, Shandong 264209, P.R. China

${ }^{2}$ Weihai Xiushui Pharmaceautical R and D Company, No. 83, Shengyang Road, Shandong 264209, P.R. China

*Corresponding author: Fax: +86 631 5688303; Tel: +86 631 5688537; E-mail: dequn.sun@sdu.edu.cn

The flumorph is a patented pesticide developed in China. This work reported the scalup preparation in which the sodamide was employed as an effective base for the condensation between diketone and acetyl morphilin. The assay and yield of the flumorph were reached over $95 \%$ and $80 \%$, respectively. This process is very competitive compared with other related methods due to lower cost and environment friendly advantages.

Keywords: Condensation, Scaleup praration, Flumorph, Sodium amide.

The flumorph is an effective pesticide, especially toward cucumber, Chinese cabbage, early blight on tomato, Phytophthora capsica and grape downy mildew ${ }^{1,2}$. In 1997, Liu reported its preparation in patent ${ }^{3}$, in which the $t$-BuONa was typically used as base for condensation of the diketone with the acetyl morphilin. However, this procedure has some shortcoming including long reaction time, low yield, many impurities in product, large amount of waste because the by-product tertiary butyl alcohol was discharged in water and was difficult to be recycled. To explore the better process, we reported ${ }^{4}$ that different base sodium sodamide $\left(\mathrm{NaNH}_{2}\right)$ was used for condensation in small scale preparation. In this work, we reported the scaleup preparation in Killab. when the sodium amide was employed as the base for the condensation to obtain flumorph. The product was obtained with assay over $95 \%$ and yield over $80 \%$, respectively.

Acetyl morphilin and sodium amide are commercially available and used without further purification. 4-Fluorine3',4'-dimethoxy benzophenone was prepared according to the reported procedure ${ }^{3}$.

Typical condensation procedure: To the solution of 4-fluorine-3',4'-dimethoxy benzophenone (130 g, $0.5 \mathrm{~mol}$ ) and morpholinoethanone (97 g, $0.75 \mathrm{~mol})$ in dry toluene (2 L) was added sodium amide $(43.2 \mathrm{~g}, 1.1 \mathrm{~mol})$ during $2 \mathrm{~h}$ under $80^{\circ} \mathrm{C}$. After addition, the solution was heated to reflux until reaction was finished (detected by TLC or HPLC). The reaction was poured into cold water $(1.8 \mathrm{~L})$. The organic phase was collected and evaporated in reduced pressure to give crude product, which was recrystallized from ethyl acetate to give $156.4 \mathrm{~g}$ flumorph as white solid, HPLC purity $95 \%$, yield $80 \%$. Two batches of this process was repeated, the HPLC purity of product were 94-96 \% and the yields were 78-81\%. The product was characterized by ${ }^{1} \mathrm{H} \mathrm{NMR}\left(400 \mathrm{MHz}, \mathrm{CDCl}_{3}\right) \delta$ ppm: 7.29-6.85 (m, 7H, Ar-H), $6.18(\mathrm{~s}, 1 \mathrm{H},=\mathrm{CH}), 3.93$ (s, $\left.3 \mathrm{H}, \mathrm{OCH}_{3}\right), 3.82\left(\mathrm{~s}, 3 \mathrm{H}, \mathrm{OCH}_{3}\right), 3.25-3.63\left(\mathrm{~m}, 8 \mathrm{H}, \mathrm{CH}_{2}\right)$, these $\mathrm{H}$ NMR value were fit in with reported data ${ }^{3}$.

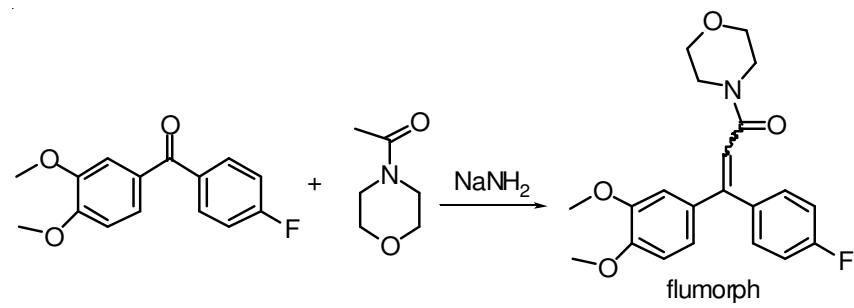

In this scaleup process, lower reation temperature was needed, also the reaction time was shortented compared with reported procedure ${ }^{3}$ while $\mathrm{NaNH}_{2}$ was used as base in condensation. The process discharged a recyclable gas wastes $\mathrm{NH}_{3}$, while in previous preparation, the by product tertiary butyl alcohol was discharged in water and not easy to be recycled. This scaleup process confirmed the our method ${ }^{4}$ is stable and repeatable (Table-1). 


\begin{tabular}{lcc}
\hline & \multicolumn{2}{c}{ TABLE-1 } \\
& COMPARATION OF THE CONDENSATION \\
\hline \multirow{2}{*}{ Condition } & \multicolumn{2}{c}{ Base } \\
\cline { 2 - 3 } & $\mathrm{NaNH}_{2}$ & $\mathrm{NaOBu}^{\mathrm{t}}[$ Ref.1] \\
\hline Reaction time & $3 \mathrm{~h}$ & $8 \mathrm{~h}$ \\
Reaction temperature & $110^{\circ} \mathrm{C}$ & $140^{\circ} \mathrm{C}$ \\
Solvent & Toluene & Dimethylbenzene \\
Yield & $80 \%$ & $60 \%$ \\
Assay & $95 \%$ & $90 \%$ \\
Waste & $\mathrm{NH}_{3}$ & $\mathrm{HOBu}^{\mathrm{t}}$ \\
\hline
\end{tabular}

merits of considerable good yield and high purity of product and disposals much less waste for environment. These advantages makes the process deserve the factory production.

\section{Conclusion}

When sodium amide was employed as base in condensation for preparation of flumorph, the process has obvious

\section{REFERENCES}

1. W.C. Liu and C.L. Liu, Pesticides, 41, 8 (2001)

2. C.L. Liu, Pesticides, 41, 47 (2002).

3. Z.C. Li, C.L.Liu and W.C. Liu, China Patent, CN 96115504.3.

4. D.Q. Sun, A.J. Tian and Y. Yang, Modern Agrochem., 8, 32 (2009). 